\title{
PENTADECAPEPTIDE BPC 157 SHORTENS DURATION OF TETRACAINE- AND OXYBUPROCAINE-INDUCED CORNEAL ANESTHESIA IN RATS
}

\author{
Ivan Mirković1,2, Tamara Kralj ${ }^{1}$, Marin Lozić ${ }^{1}$, Vasilije Stambolija ${ }^{1}$, Josip Kovačević ${ }^{1}$, \\ Luka Vrdoljak ${ }^{1}$, Mirna Zlatar ${ }^{1}$, Kristina Milanović ${ }^{2}$ Domagoj Drmić ${ }^{1}$, Jurica Predović ${ }^{3}$, \\ Sanja Masnec ${ }^{4}$, Matija Jurjević ${ }^{2}$, Mladen Bušić ${ }^{3}$, Sven Seiwerth ${ }^{1}$, Antonio Kokot ${ }^{1,2}$ and Predrag Sikirić ${ }^{1}$ \\ ${ }^{1}$ Department of Pharmacology, School of Medicine, University of Zagreb, Zagreb, Croatia; \\ ${ }^{2}$ Department of Anatomy and Neuroscience, Osijek Faculty of Medicine, \\ Josip Juraj Strossmayer University of Osijek, Osijek, Croatia; \\ ${ }^{3}$ Department of Ophthalmology, Sveti Duh University Hospital, Zagreb, Croatia; \\ ${ }^{4}$ Department of Ophthalmology, Zagreb University Hospital Centre, Zagreb, Croatia
}

SUMMARY - We focused on the relationship of $0.5 \%$ tetracaine- and $0.4 \%$ oxybuprocaine-in-

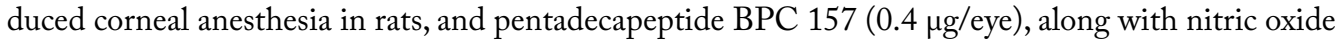
synthase (NOS) inhibitor N(gamma)-nitro-L-arginine methyl ester (L-NAME) (0.1 mg/eye) and/or NOS substrate L-arginine ( $2 \mathrm{mg} / \mathrm{eye})$, applied in the form of eye drops. We assessed corneal sensitivity recovery (Cochet-Bonnet esthesiometer), corneal lesion elimination (staining with $10 \%$ fluorescein) and decrease in tear volume (Schirmer test). BPC 157 administration had a full counteracting effect. Recovery also occurred in the presence of NOS blockade and NOS substrate application. Larginine eventually shortened duration of corneal insensitivity and exerted corneal lesion counteraction (and counteraction of tetracaine-induced decrease of tear volume) only in earlier but not in later period. L-NAME application led to longer duration of corneal insensitivity, increase in corneal lesions and decrease in tear volume. When L-NAME and L-arginine were applied together, they antagonized each other's effect. These distinctions may indicate particular NOS involvement (corneal insensitivity vs. corneal lesion along with tear production), distinctively affected by the administration of NO agents. However, additional BPC 157 co-administration would re-establish counteraction over topical ophthalmic anesthetic-induced effect, be it in its early or late course. We suggest BPC 157 as an antidote to topical ophthalmic anesthetics.

Key words: BPC 157; Tetracaine; Oxybuprocaine; Corneal anesthesia; NOS; Rats

\section{Introduction}

Our study was focused on counteracting corneal anesthesia using the stable gastric pentadecapeptide BPC 157, N(gamma)-nitro-L-arginine methyl ester

Correspondence to: Assist. Prof. Antonio Kokot, $M D, P h D$, Department of Anatomy and Neuroscience, Department of Ophthalmology, Osijek Faculty of Medicine, Josip Juraj Strossmayer University of Osijek, Josipa Huttlera 4, HR-31000 Osijek, Croatia

E-mail: antonio.kokot@mefos.hr

Received December 31, 2019, accepted January 31, 2020
(L-NAME) and/or L-arginine in rats ${ }^{1-13}$. After the stable gastric pentadecapeptide BPC $157^{1-13}$ has been demonstrated to act as a potential antidote to bupivacaine cardiotoxicity, thereby interacting with local anesthetics ${ }^{14}$, we focused on the potential counteracting effect of the stable gastric pentadecapeptide BPC 157 and tetracaine as a topical ophthalmic anesthetic applied onto the eye surface. That counteracting effect may be related to the nitric oxide synthase (NOS) $)^{1-13}$, as follows from the BPC 157 application with NO agents, NOS blocker L-NAME and NOS substrate 
L-arginine, administered alone and/or in combination. Such a counteracting effect may also have a more general significance, providing additional antagonizing the oxybuprocaine-induced corneal anesthesia, and the corresponding effect of the NO agents, L-NAME and $\mathrm{L}$-arginine, administered alone and/or in combination.

Indicatively, counteraction of bupivacaine arrhythmias ${ }^{14}$ may be seen as part of the larger beneficial effect providing that BPC 157 counteracts various arrhyth$\operatorname{mias}^{14-19}$. Likewise, with BPC 157 application, counteraction of tetracaine- and oxybuprocaine-induced corneal anesthesia may appear along with healing of perforating corneal injury and total debridement of corneal epithelium, thus maintaining corneal transparency ${ }^{20,21}$. BPC 157 counteracts the damaging effects of lacrimal gland extirpation and dry eye syndrome in rats $^{22}$. We also revealed NOS dependence of atropineinduced mydriasis and L-NAME- and L-arginineinduced miosis and reversal by the pentadecapeptide BPC 157 in both rats and guinea pigs ${ }^{23}$. This may be particularly important considering corneal lesions that may be induced by local anesthetic application ${ }^{24-27}$.

As an original antiulcer peptide, BPC 157 has virtually no known toxicity of its own, the lethal dose (LD) value has not yet been established, and there were no side effects in clinical trials such as ulcerative colitis and multiple sclerosis ${ }^{1-13}$. Also indicative of special relation, BPC 157 caused significant antagonism of general anesthesia produced by thiopental with a parallel shift of the dose-response curve to the right, manipulating in both ways with NOS activity modulation (especially, the potentiating effects of L-NAME were abolished ${ }^{28}$. This counteraction was observed, along with the evidence that BPC 157 largely interacts with NOS in different models and species ${ }^{1-13}$.

On the other hand, BPC 157 produced analgesia in the $\mathrm{MgSO} 4$ and acetic acid test in mice, a model of prolonged pain associated with tissue injury ${ }^{29}$. This indicates that BPC 157 may have local anesthetic activity of its own.

Thus, to counteract tetracaine- and oxybuprocaineinduced corneal anesthesia, the previously reported effective dose regimens of the pentadecapeptide BPC 157 $7^{14-19}$, along with NOS inhibitor L-NAME and NOS substrate L-arginine, were administered after tetracaine and oxybuprocaine application in rats.

\section{Methods}

\section{Animals}

Wistar Albino male rats (200 g b.w.) were randomly assigned to the experiments (6 animals at least per experimental group and interval), all of which were approved by the local Ethics Committee of the School of Medicine, University of Zagreb, Zagreb, Croatia (No. 380-59-10106-19-111/100; 641-01/19-02/01). Furthermore, all experiments were carried out under blind protocol and the effect was assessed by examiners who were completely unaware of the given protocol. The research and experiments also followed the ARVO Statement for the Use of Animals in Ophthalmic and Vision Research.

\section{Drugs and experimental protocol}

Pentadecapeptide BPC 157 (GEPPPGKPADDAGLV, M.W. 1419, Diagen, Ljubljana, Slovenia) dissolved in saline was used in all experiments. The BPC 157 peptide is part of the sequence of human gastric juice BPC protein and is freely soluble in water at $\mathrm{pH} 7.0$ and saline. It was prepared as described previously with $99 \%$ high-pressure liquid chromatography (HPLC) purity, expressing 1-des-Gly peptide as an impurity ${ }^{14-19}$. At 15 minutes after diazepam ( $5 \mathrm{mg} /$ $\mathrm{kg}$ intraperitoneally), two drops of $0.5 \%$ tetracaine (Tetrakain 0.5\%, Gradska ljekarna, Zagreb, Croatia) or oxybuprocaine $0.4 \%$ (Novesine $0.4 \%$, OmniVision, Munich, Germany) were administered into each eye. At 1 minute, rats received pentadecapeptide BPC 157 (0.4 $\mu \mathrm{g} /$ eye), L-NAME (0.1 mg/eye) and L-arginine ( $2 \mathrm{mg} /$ eye), administered alone and in combination. The agents were administered locally (two drops/eye) (Sigma Aldrich, St. Louis, USA), while controls received a respective saline volume.

\section{Corneal sensitivity measurement}

Using the Cochet-Bonnet esthesiometer (Luneau Ophtalmologie, Chartres, France), a corneal sensitivity measurement device ${ }^{24}$, corneal sensitivity was measured in rats administered $0.5 \%$ tetracaine or $0.4 \%$ oxybuprocaine before corneal anesthesia, then after tetracaine or oxybuprocaine application, before therapy application, at $1 \mathrm{~min}$, and with therapy application, at 5 -minute intervals until full sensitivity was restored.

Briefly, the Cochet-Bonnet esthesiometer consists of nylon monofilament that can be pulled out and pro- 
Table 1. $0.5 \%$ tetracaine induced corneal anesthesia in rats and effect of pentadecapeptide

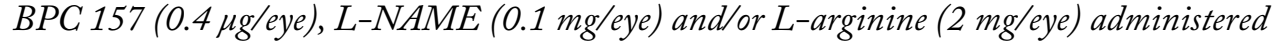
alone or in combination after complete corneal anesthesia was established, at $1 \mathrm{~min}$ after $0.5 \%$ tetracaine

\begin{tabular}{|c|c|c|}
\hline \multirow{2}{*}{$\begin{array}{l}\text { Pentadecapeptide BPC } 157 \text { ( } 0.4 \mu \mathrm{g} / \text { eye }), \mathrm{L}-\mathrm{NAME} \\
(0.1 \mathrm{mg} / \text { eye }), \mathrm{L} \text {-arginine }(2 \mathrm{mg} \text { /eye), administered alone } \\
\text { and in combination after complete corneal anesthesia was } \\
\text { established, at } 1 \mathrm{~min} \text { after } 0.5 \% \text { tetracaine }\end{array}$} & \multicolumn{2}{|c|}{$\begin{array}{l}\text { Duration of } 0.5 \% \text { tetracaine } \\
\text { corneal anesthesia }\end{array}$} \\
\hline & $\begin{array}{l}\mathrm{T} 1(\min ) \\
\text { mean } \pm \mathrm{SD}\end{array}$ & $\begin{array}{l}\text { T4 (min), } \\
\text { mean } \pm \text { SD }\end{array}$ \\
\hline Saline & $59 \pm 5.2$ & $109 \pm 12.5$ \\
\hline BPC 157 & $45 \pm 4.6^{*}$ & $94 \pm 7.0^{*}$ \\
\hline L-arginine & $51 \pm 8.5^{*}$ & $90 \pm 5.3^{*}$ \\
\hline L-arginine + BPC 157 & $34 \pm 5.8^{* \#}$ & $72 \pm 5.8^{* \#}$ \\
\hline L-NAME & $84 \pm 7.7^{*}$ & $126 \pm 8.4^{*}$ \\
\hline L-NAME + BPC 157 & $65 \pm 7.1^{\#}$ & $100 \pm 9.4^{\#}$ \\
\hline L-arginine + L-NAME & $73 \pm 8.6^{*+}$ & $123 \pm 8.2^{*_{+}}$ \\
\hline L-arginine + L-NAME + BPC 157 & $44 \pm 3.9^{* \#}$ & $91 \pm 8.4^{* \#}$ \\
\hline
\end{tabular}

$\mathrm{T} 1$ = time point when blink response to maximal corneal stimulation appeared again; $\mathrm{T} 4$ = time point when corneal sensitivity returned to baseline values; $\mathrm{T} 1-\mathrm{T} 4=$ complete corneal anesthesia duration (minutes, mean $\pm \mathrm{SD}$ ); " $\mathrm{p}<0.05$ vs. saline (control); ${ }^{\mathrm{p}} \mathrm{p}<0.05$ vs. corresponding 'non-BPC 157 group'; 'p<0.05 vs. corresponding 'L-NAME-group'; Mann-Whitney test for independent samples followed by Benjamini and Hochberg procedure to control the false discovery rate (FDR)

duces a pressure force at its top, which is inversely proportional to the length of the elongated portion of the monofilament. The nylon filament is $0.12 \mathrm{~mm}$ in diameter and is $6 \mathrm{~cm}$ long. Corneal sensitivity testing started with gentle touch of the fully extended tip of the esthesiometer perpendicular to the cornea and applying a small force to finely distort the filament. If the rat blinked, it was recorded as a positive response. If the blinking response was absent, filament length was reduced by 1 centimeter and the procedure was repeated until a positive response was obtained. The absence of positive response when the filament length is 1 centimeter is defined as complete block. The length of filament in centimeters that caused positive response was recorded. In the case of complete block, the value 0 was recorded. As mentioned, after initial corneal sensitivity testing, each eye was tested at 5-min intervals until full sensitivity was restored.

\section{Corneal epithelium defect assessment}

In rats administered $0.5 \%$ tetracaine that received saline or BPC 157, L-NAME and/or L-arginine eye drops as described above, corneal epithelium defects considering long-term exposure were assessed at 30 ,
60 and 150 minutes of the experiment. Corneal epithelium defects were monitored by slit lamp (PSL Portable Slit Lamp, Reichert, Buffalo, USA) with blue cobalt filter and by photographing the lesions after staining with standard 10\% fluorescein (Alcon, Geneva, Switzerland), according to the experimental protocol. The test was positive if there was an epithelial defect and negative if there was no epithelial defect. Scoring is performed by assessing the area affected with corneal defects divided in quarters, from no defects $(0 / 4)$ to the whole area of the cornea being affected with epithelium defects (4/4).

\section{Schirmer test assessment}

Schirmer test was performed at 30,60 and $120 \mathrm{~min}$ in $0.5 \%$ tetracaine rats that received saline or BPC 157, L-NAME and/or L-arginine eye drops as described above ${ }^{30}$. Standard Schirmer tracks using 2-mm wide test strips cut from Schirmer test paper to fit the size of the rat eye were inserted $1 \mathrm{~mm}$ into the inferior conjunctival fornix and placed for 5 minutes, after which results in millimeters were recorded (the values of $5.5 \pm 1.0 \mathrm{~mm}$ obtained in healthy rats were considered normal). 
Table 2. $0.4 \%$ oxybuprocaine induced corneal anesthesia in rats and effect of pentadecapeptide

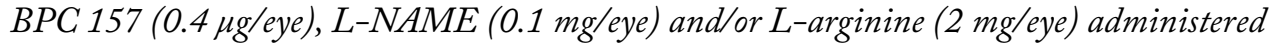
alone and in combination after complete corneal anesthesia was established, at $1 \mathrm{~min}$ after $0.4 \%$ oxybuprocaine

\begin{tabular}{|c|c|c|}
\hline \multirow{2}{*}{$\begin{array}{l}\text { Pentadecapeptide BPC } 157 \text { ( } 0.4 \mu \mathrm{g} / \text { eye }) \text {, L-NAME } \\
(0.1 \mathrm{mg} \text { /eye), L-arginine ( } 2 \mathrm{mg} / \text { eye), administered } \\
\text { alone and in combination after complete corneal } \\
\text { anesthesia was established, at } 1 \mathrm{~min} \text { after } 0.4 \% \\
\text { oxybuprocaine corneal anesthesia }\end{array}$} & \multicolumn{2}{|c|}{$\begin{array}{l}\text { Duration of } 0.4 \% \text { oxybuprocaine } \\
\text { corneal anesthesia }\end{array}$} \\
\hline & $\begin{array}{l}\mathrm{T} 1(\min ) \\
\text { mean } \pm \mathrm{SD}\end{array}$ & $\begin{array}{l}\mathrm{T} 4(\min ) \\
\text { mean } \pm \mathrm{SD}\end{array}$ \\
\hline Saline & $64 \pm 5.7$ & $126 \pm 3.9$ \\
\hline BPC 157 & $51 \pm 5.0^{*}$ & $106 \pm 7.4^{*}$ \\
\hline L-arginine & $56 \pm 6.9^{*}$ & $112 \pm 5.9^{*}$ \\
\hline L-arginine + BPC 157 & $48 \pm 5.9^{* \#}$ & $96 \pm 5.5^{* \#}$ \\
\hline L-NAME & $89 \pm 5.7^{*}$ & $137 \pm 7.9^{*}$ \\
\hline L-NAME + BPC 157 & $71 \pm 7.6^{\#}$ & $104 \pm 7.0^{* \#}$ \\
\hline L-arginine + L-NAME & $77 \pm 6.7^{*+}$ & $131 \pm 8.0$ \\
\hline L-arginine + L-NAME + BPC 157 & $60 \pm 7.2^{\#}$ & $98 \pm 6.7^{* \#}$ \\
\hline
\end{tabular}

$\mathrm{T} 1$ = time point when blink response to maximal corneal stimulation appeared again; $\mathrm{T} 4$ = time point when corneal sensitivity returned to baseline values; T1-T4 = complete corneal anesthesia duration (minutes, mean $\pm \mathrm{SD}$ ); ${ }^{*} \mathrm{p}<0.05$ vs. saline (control); ${ }^{*} \mathrm{p}<0.05$ vs. corresponding 'non-BPC 157 group' ${ }^{+} \mathrm{p}<0.05$ vs. corresponding 'L-NAME-group'; Mann-Whitney test for independent samples followed by Benjamini and Hochberg procedure to control the false discovery rate (FDR)

\section{Statistical analysis}

Data were processed by use of descriptive statistics according to their distribution (Kolmogorov-Smirnov test for normal distribution). The duration of complete corneal anesthesia (T1) and time interval until corneal sensitivity returned to baseline values (T4) for two different local anesthetic drugs (tetracaine and oxybuprocaine) in regard to different adjuvants (saline, BPC, $\mathrm{L}$-arginine, L-NAME, and their combinations) were explored by the analysis of variance (ANOVA). Differences in the effect of individual adjuvants and their combination on the duration of tetracaine/oxybuprocaine induced corneal anesthesia were analyzed in detail using the Mann-Whitney test for independent samples, followed by Benjamini and Hochberg procedure to control false discovery rate (FDR). All statistical analyses were performed using MedCalc 9.5.1.0 (MedCalc Software, Mariakerke, Belgium). The values of $\mathrm{p}<0.05$ were considered statistically significant.

\section{Results}

We focused on therapy relation between the stable gastric pentadecapeptide BPC 157, L-NAME and L- arginine, applied alone and/or in combination, and corneal anesthesia in rats (Tables 1-3, Figs. 1-4).

\section{Corneal sensitivity measurement}

A quite long-lasting corneal insensitivity was induced by $0.5 \%$ tetracaine or $0.4 \%$ oxybuprocaine in each eye and measured using the Cochet-Bonnet esthesiometer (Tables 1-2, Figs. 1-2). At 1 minute after two drops of $0.5 \%$ tetracaine or $0.4 \%$ oxybuprocaine in each eye, rats received locally (two drops/eye) pentadecapeptide BPC 157, L-NAME, L-arginine, administered alone and in combination. BPC 157 applied as eye drops consistently recovered corneal sensitivity in both tetracaine- and oxybuprocaine-rats. In tetracaine-rats and oxybuprocaine-rats, an indicative point was that the full counteracting effect of the BPC 157 administration also occurred in the presence of NOS-blockade (L-NAME+BPC 157), as well as in NOS-substrate application (L-arginine+BPC 157). L-arginine eventually shortened the duration of corneal insensitivity. Lengthening of corneal insensitivity appeared after L-NAME. When L-NAME and Larginine were given together (L-NAME+L-arginine), they antagonized each other's effect (i.e. NOS specific 
Table 3. 0.5\% tetracaine corneal anesthesia in rats and effect of pentadecapeptide BPC 157 (0.4 $\mu \mathrm{g} /$ eye), L-NAME $(0.1 \mathrm{mg} /$ eye $)$ and/or L-arginine (2 $\mathrm{mg} /$ eye) administered alone and in combination after complete corneal anesthesia was established, at 1 min after $0.5 \%$ tetracaine

\begin{tabular}{|l|l|l|l|}
\hline $\begin{array}{l}\text { Pentadecapeptide BPC } 157 \text { (0.4 } \mu \mathrm{g} / \text { eye), L-NAME (0.1 mg/eye), } \\
\text { L-arginine (2 mg/eye) administered alone and in combination after } \\
\text { complete corneal anesthesia was established, at } 1 \text { min after 0.5\% tetracaine }\end{array}$ & At 30 min & At 60 min & At 150 min \\
\hline Saline & $2.5 \pm 0.5$ & $2.0 \pm 0.6$ & $2.0 \pm 0.6$ \\
BPC 157 & $6.5 \pm 0.5^{*}$ & $5.0 \pm 0.6^{*}$ & $5.5 \pm 0.5^{*}$ \\
L-arginine & $5.5 \pm 0.5^{*}$ & $3.5 \pm 0.5^{*}$ & $3.0 \pm 0.9$ \\
L-arginine + BPC 157 & $5.5 \pm 0.5^{*}$ & $6.0 \pm 0.6^{*}$ & $6.0 \pm 0.6^{*}$ \\
L-NAME & $3.5 \pm 0.5^{*}$ & $2.5 \pm 0.5$ & $1.0 \pm 0.6^{*}$ \\
L-NAME + BPC 157 & $4.0 \pm 0.6^{*}$ & $4.5 \pm 0.5^{*}$ & $5.5 \pm 0.5^{*}$ \\
L-arginine + L-NAME & $4.0 \pm 0.6^{*}$ & $4.0 \pm 0.9^{*}$ & $5.0 \pm 0.9^{*}$ \\
L-arginine + L-NAME + BPC 157 & $4.5 \pm 0.8^{*}$ & $4.5 \pm 0.5^{*}$ & $5.5 \pm 0.5^{*}$ \\
\hline
\end{tabular}

Standard Schirmer tracks using $2 \mathrm{~mm}$-wide test strips cut from Schirmer test paper to fit the size of the rat's eye were inserted $1 \mathrm{~mm}$ into the inferior conjunctival fornix and placed for 5 minutes after which results in millimeters (mean $\pm \mathrm{SD})$ were read; ${ }^{*} \mathrm{p}<0.05$ vs. saline (control); Mann-Whitney test for independent samples followed by Benjamini and Hochberg procedure to control false discovery rate (FDR)

effect), but these rats still exhibited lengthening of corneal insensitivity. Additional BPC 157 co-application (L-NAME+L-arginine+BPC 157) would have re-established counteraction over topical ophthalmic anesthetic-induced corneal insensitivity.

\section{Corneal epithelium defect assessment}

A quite long-lasting $0.5 \%$ tetracaine corneal insensitivity was soon associated with development of corneal lesions, sustained consistently until the end of the experiment, which was markedly influenced by pentadecapeptide BPC 157, L-NAME and L-arginine administered alone and in combination (Figs. 3-4). Much like corneal insensitivity, BPC 157 applied as eye drops consistently reduced development of corneal lesions. Likewise, the full counteracting effect of the BPC 157 administration also occurred in the presence of NOS-blockade (L-NAME+BPC 157), as well as in NOS-substrate application (L-arginine+BPC 157). $\mathrm{L}$-arginine that markedly shortened the duration of corneal insensitivity had only temporary effect on corneal lesions, unable to counteract final lesions. Consistent lengthening of corneal insensitivity with LNAME was associated with initial protection reversed to subsequent aggravation. When L-NAME and Larginine were given together (L-NAME+L-arginine), their mutual antagonizing ensured that these rats, which exhibited lengthening of corneal insensitivity, consistently had fewer lesions. Additional BPC 157 co-application (L-NAME+L-arginine+BPC 157) resulted consistently in fewer lesions.

\section{Schirmer test assessment}

Schirmer test showed that tetracaine application consistently decreased tear volume (Table 3). BPC 157 application completely counteracted tetracaine-induced decrease of tear volume and maintained normal healthy values. L-arginine counteracted tetracaine-induced decrease of tear volume only at the earliest interval. L-NAME initially counteracted but later even augmented tetracaine-induced decrease of tear volume. When given together, $\mathrm{L}-\mathrm{NAME}+\mathrm{L}$-arginine, they consistently counteracted tetracaine-induced decrease of tear volume. Additional BPC 157 co-application (L-NAME+BPC 157, L-arginine+BPC 157, $\mathrm{L}-\mathrm{NAME}+\mathrm{L}$-arginine+BPC 157) consistently counteracted tetracaine-induced decrease of tear volume.

\section{Discussion}

With the investigated topical ophthalmic anesthetics applied on the surface of the eye and known to act by blocking sodium channels in neuronal axons, thus preventing conduction along the axons and keeping the brain from detecting painful stimuli ${ }^{26}$, BPC 157 applied as eye drops has a particular counteracting 


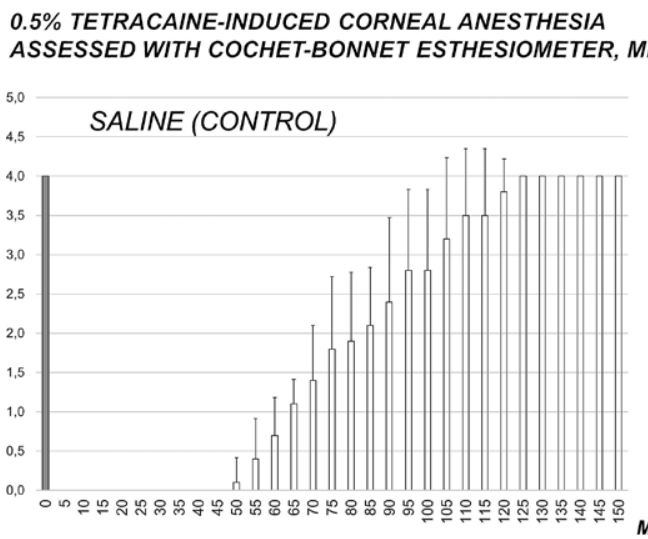

\section{$M E A N S \pm S D$}
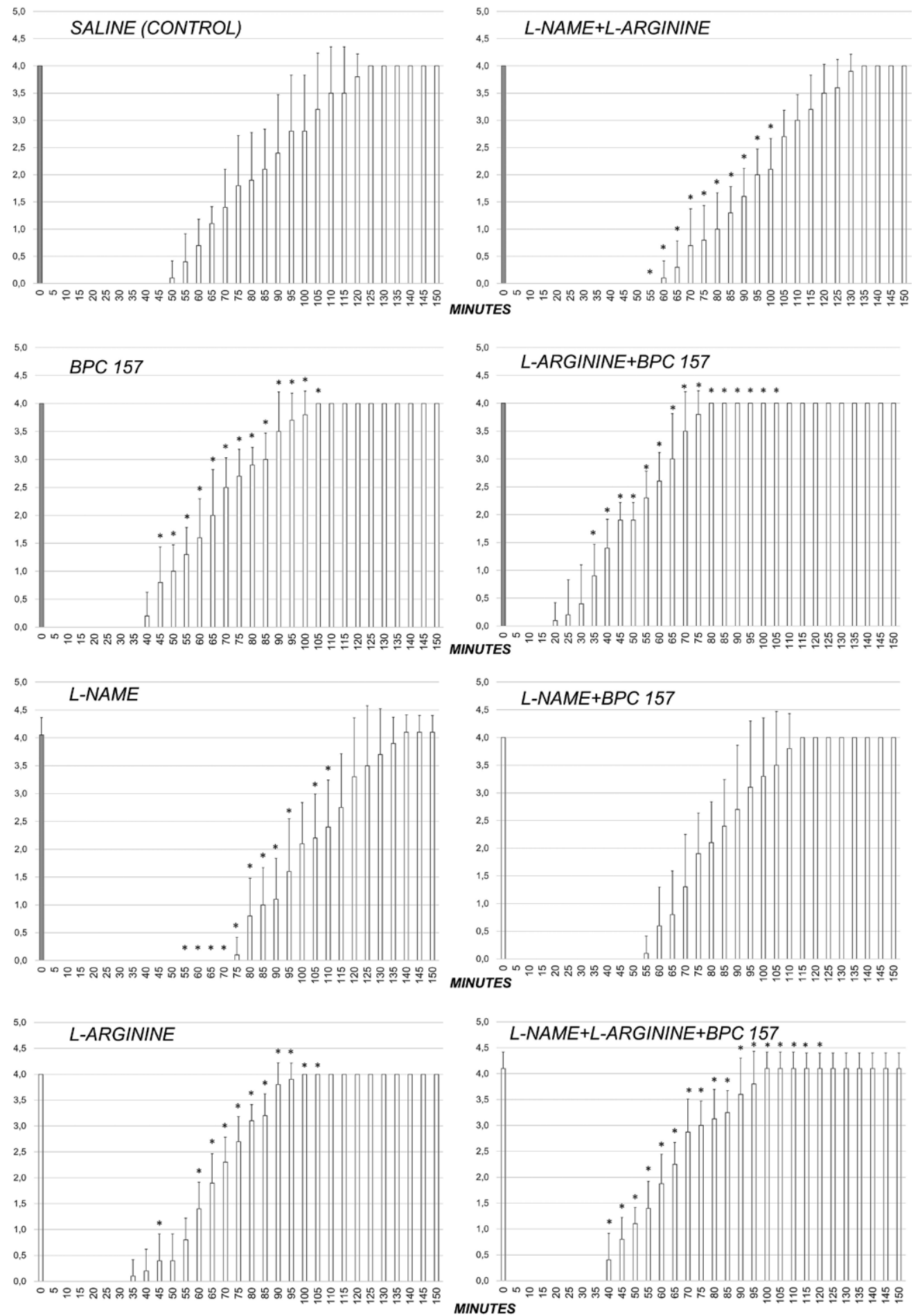

Fig. 1. Complete course of $0.5 \%$ tetracaine corneal anesthesia in rats and effect of pentadecapeptide

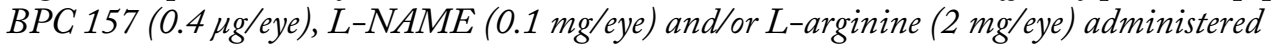
alone and in combination after complete corneal anesthesia was established, at 1 min after $0.5 \%$ tetracaine. After initial corneal sensitivity testing, each eye was tested at 5-minute intervals until full sensitivity was restored; ${ }^{*} p<0.05$ vs. saline (control). 


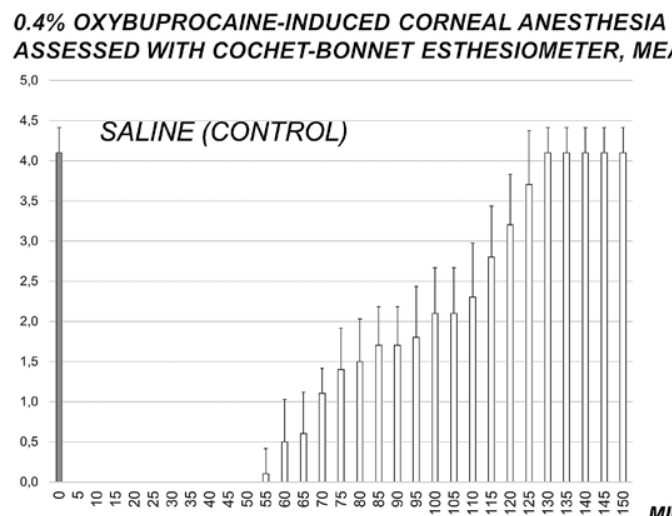

\section{ANS $\pm S D$}
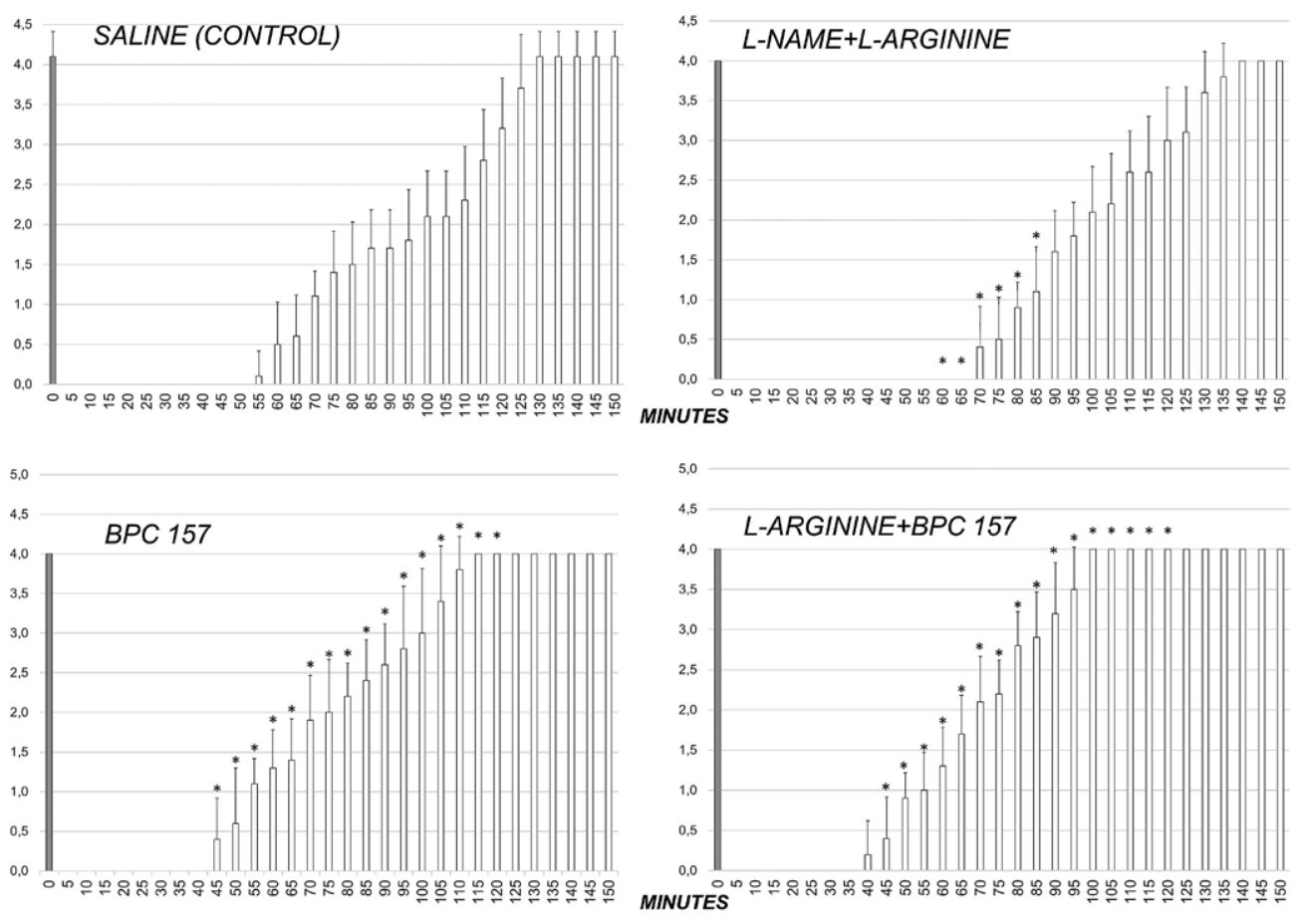

MINUTES
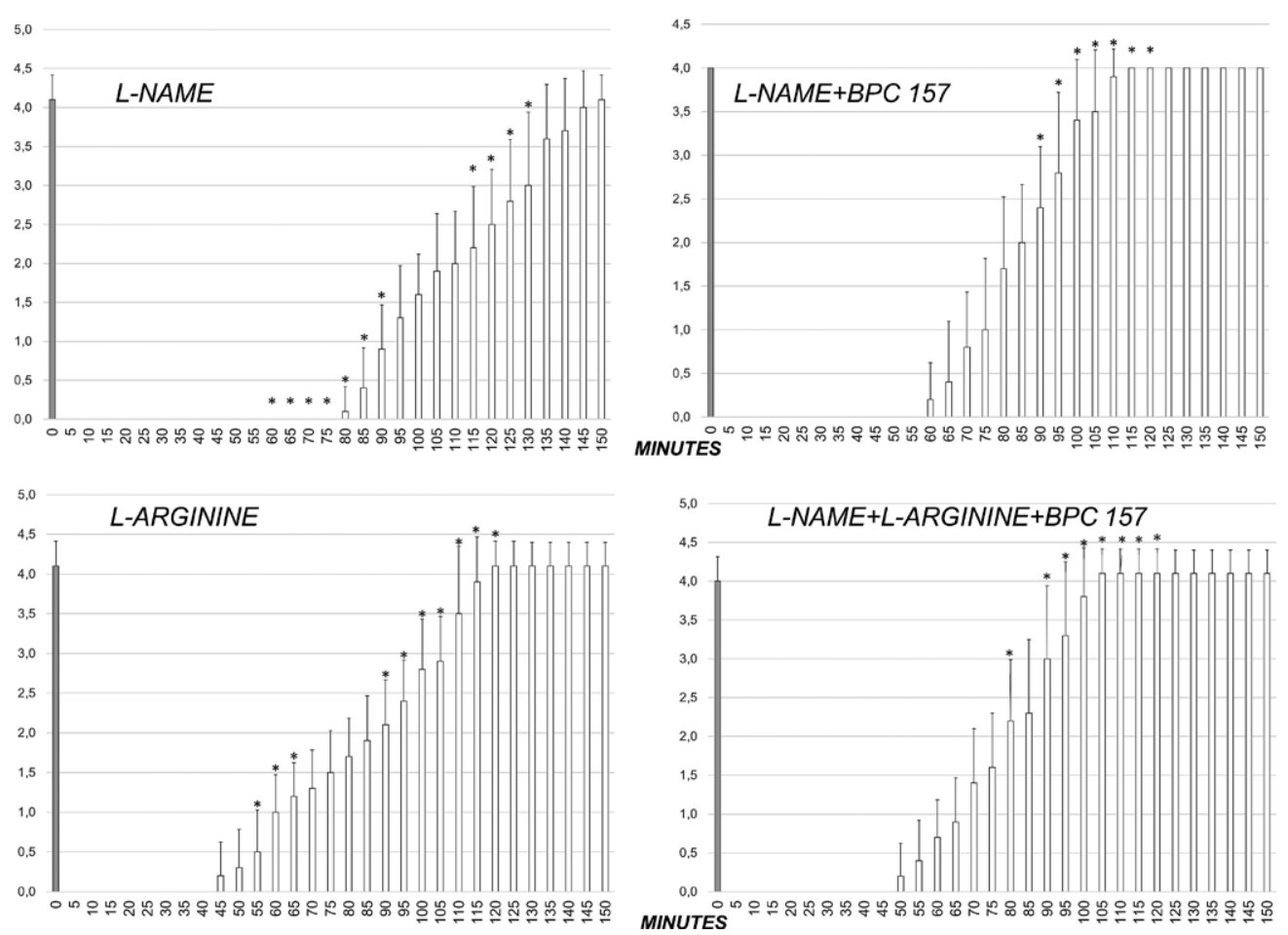

Fig. 2. Complete course of $0.4 \%$ oxybuprocaine corneal anesthesia in rats and effect of

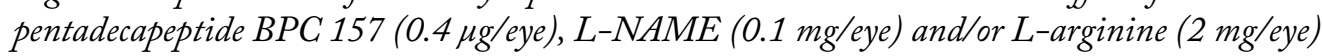
administered alone and in combination after complete corneal anesthesia was established, at 1 min after $0.4 \%$ oxybuprocaine corneal anesthesia. After initial corneal sensitivity testing, each eye was tested at 5-minute intervals until full sensitivity was restored; ${ }^{*}<0.05$ vs. saline (control). 
CORNEAL EPITHELIUM DEFECTS, SCORED 0-4, MIN/MED/MAX
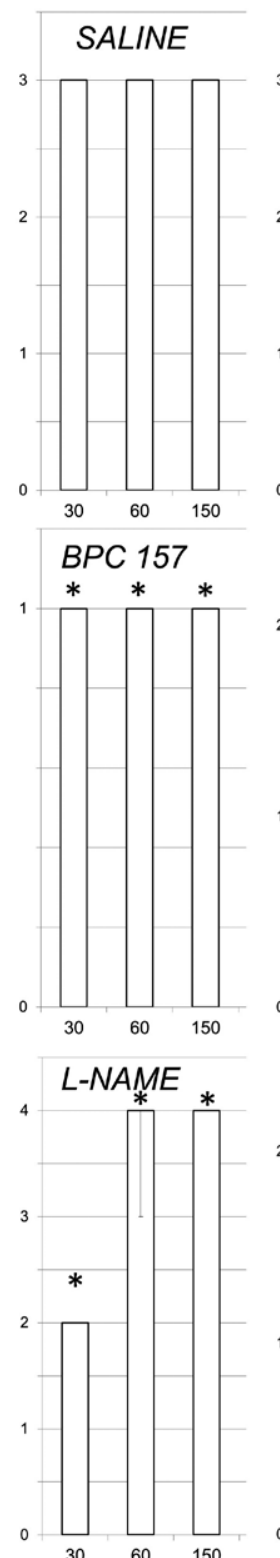

L-ARGININE

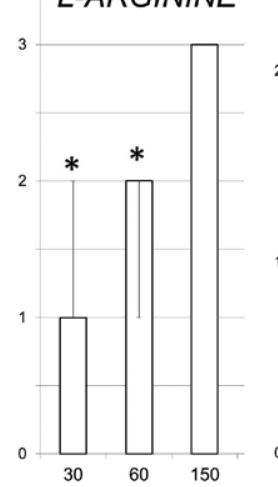

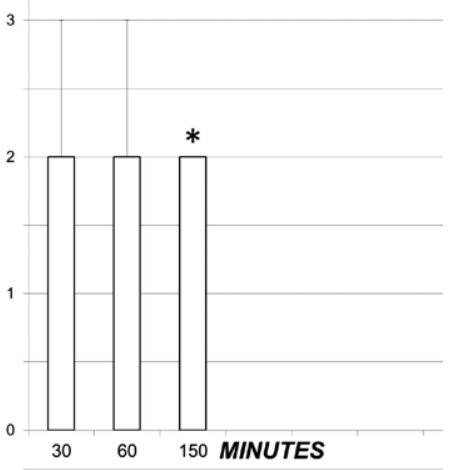

L-ARGININE+BPC 157

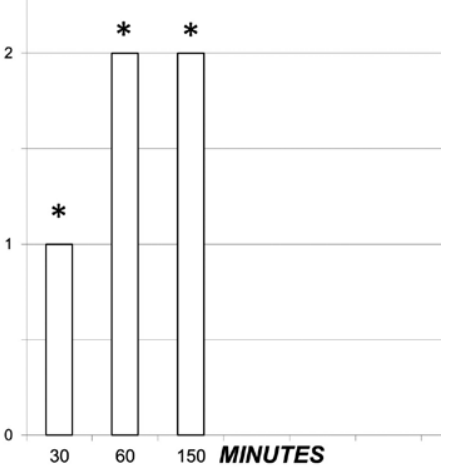

L-NAME+BPC 157

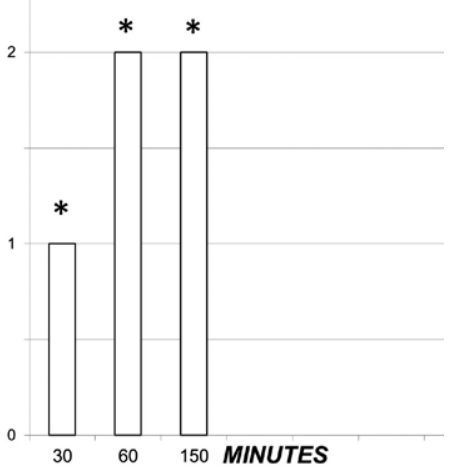

\section{L-NAME+L-ARGININE}

L-NAME+L-ARGININE

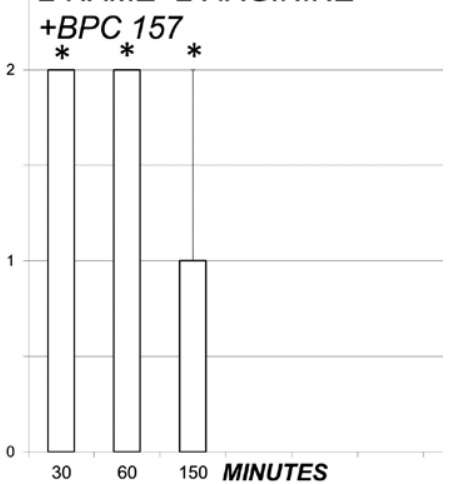

action. It recovers corneal sensitivity, markedly eliminates corneal lesions, and counteracts decrease of tear volume by interacting with NOS. Likely, this particular action may be consequential to the interference with the essential action of local anesthetics.

Of note, we should appreciate the BPC 157 actions responsible for healing of the perforating corneal injury and total debridement of corneal epithelium and maintained corneal transparency, or BPC 157 counteraction of the damaging effects of lacrimal gland extirpation and dry eye syndrome in rats ${ }^{20-22}$. These actions against topical ophthalmic anesthetics may be sustained, thus preventing the otherwise inescapable direct epithelial toxicity that would lead to corneal drying due to the loss of corneal sensation, causing subsequent decrease in blink rate and tear production.

Thus, we recorded lesion counteraction and eventually less lesion formation in both tetracaine-rats and oxybuprocaine-rats administered BPC 157 therapy. In addition, BPC 157 markedly interferes with atropine effects, reduces atropine-induced mydriasis, and thereby it may increase tear volume once it has been decreased with the application of topical ophthalmic anesthetics on the surface of the eye.

As mentioned above, BPC 157 largely interacts with NOS in different models and species, with both $\mathrm{L}-\mathrm{NAME}$ and L-arginine effects ${ }^{1-13}$. In tetracaine-rats and oxybuprocaine-rats, an indicative point is that the full counteracting effect of BPC 157 administration also occurs in the presence of NOS blockade (LNAME+BPC 157) and NOS substrate application (L-arginine+BPC 157). Moreover, it occurs in the circumstances of particular NOS involvement. While both antagonize atropine-induced mydriasis ${ }^{23}$, after topical ophthalmic anesthetics L-NAME and L-arginine they have a distinctive effect on corneal insensitivity duration, rate of corneal lesions and tear volume.

Fig. 3. Corneal epithelium defects, scored 0-4 (Min/Med/Max), course with 0.5\% tetracaine corneal anesthesia in rats and effect of pentadecapeptide BPC 157 (0.4 $\mu \mathrm{g}$ /eye), L-NAME (0.1 mg/eye) and/or L-arginine (2 mg/eye) administered alone and in combination after complete corneal anesthesia was established, at 1 min after $0.5 \%$ tetracaine corneal anesthesia. After initial corneal sensitivity testing, each eye was tested at 5-minute intervals until full sensitivity was restored; ${ }^{*} p<0.05$ vs. saline (control). 


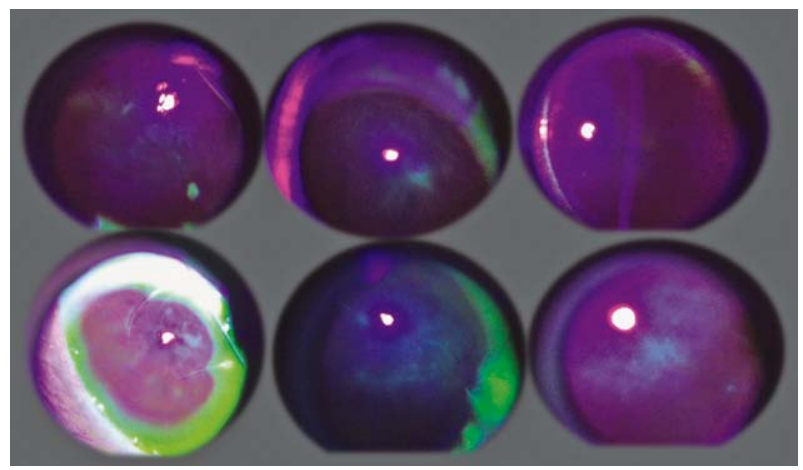

Fig. 4. Illustrative presentation of the course of corneal defects with 0.5\% tetracaine corneal anesthesia in BPC 157 treated rats (upper) and control rats (lower), at 30 (left), 60 (middle) and 150 (right) minutes after 0.5\% tetracaine. Corneal epithelium defects were monitored by slit lamp (PSL Portable Slit Lamp, Reichert, Buffalo, USA) with blue cobalt filter and by photographing the lesions after staining with standard 10\% fluorescein (Alcon, Geneva, Switzerland) according to the experimental protocol.

L-arginine eventually shortens duration of corneal insensitivity, shows counteraction to corneal lesions (and counteraction of tetracaine-induced decrease in tear volume), however, only in the early but not in later period. L-NAME application was associated with prolonged corneal insensitivity, higher rate of corneal lesions and reduction of tear volume. When L-NAME and $\mathrm{L}$-arginine were given together $(\mathrm{L}-\mathrm{NAME}+\mathrm{L}-$ arginine), they antagonized each other's effect (i.e. NOS specific effect), and these rats exhibited lengthening of corneal insensitivity, but had less corneal lesions. They also counteracted tetracaine-induced decrease of tear volume. Thus, with corneal insensitivity, L-NAME effect prevailed over L-arginine effect; with less corneal lesions, $\mathrm{L}$-arginine effect prevailed over LNAME effect. This distinctive effect (corneal insensitivity, corneal lesion, tear formation) may indicate particular NOS involvement (corneal insensitivity vs. corneal lesion along with tear formation) that may be distinctively affected by the application of NO agents. Anyway, be it in the early or late course, additional BPC 157 co-application (L-NAME+L-arginine+BPC 157) would have re-established counteraction over topical ophthalmic anesthetic-induced effects (i.e. particular BPC 157 to NOS relations).

Of note, distinctive NOS presentation was also recorded in other studies with various models ${ }^{23,31-34}$. This provides a common model ${ }^{23,31-34}$ that supports particular NOS involvement also beyond the topical ophthalmic anesthetic-induced adverse effects. On the other hand, this combined point observed with BPC 157 administration implicates its particular relations with topical ophthalmic anesthetics and possible counteraction of their adverse effects. Unlike topical ophthalmic anesthetic inhibition, with the open eye, there are light-evoked increases in tear volume ${ }^{35}$, thus BPC 157 can permanently (L-arginine only temporarily) evoke protective reflexes such as lacrimation.

The noted counteraction of severe cardiac disturbances (bradycardia, prolongation of all of the observed waves and intervals, AV-block, ventricular ectopy, ventricular tachycardia, T-wave elevation and asystole) after bupivacaine (and counteraction of other various arrhythmias $)^{14-19}$ appears much like counteraction of adverse effects of tetracaine and oxybuprocaine topical ophthalmic anesthetics applied on the surface of the eye. Greater bupivacaine potential of direct cardiac toxicity than other agents, greater affinity for inactive and resting sodium channel configurations and slower dissociation from these channels ${ }^{36}$ together support an even more effective counteraction of all tetracaine- and oxybuprocaine-induced adverse effects, as recorded in our study. Moreover, these findings approach the BPC 157 counteracting effect on the essential chain of the events following local anesthetic application $^{36,37}$. These may be essential for penetration of both the epineurium and neuronal membrane, duration of the action by the time that local anesthetic remains in close proximity to neural fibers, and tetracaine lipid solubility and neuronal protein binding resulting in a local anesthetic that is more potent with an extended duration of action ${ }^{38}$.

Of note, in corneal innervation studies ${ }^{39-41}$, mechanical threshold assessed by Belmonte esthesiometer provides structural and functional correlation, and thus corneal nerve function maintenance and recovery. In systemic terms, this may explain why BPC 157 produced analgesia in the $\mathrm{MgSO} 4$ and acetic acid intraperitoneal test ${ }^{29}$, and counteracted peritonitis in several models ${ }^{31-33,42}$.

Likewise, in rats with severed sciatic nerve, BPC 157 markedly improves nerve healing and counteracts autotomy ${ }^{43}$ that reflects chronic neuropathic pain, neuroma at the proximal nerve stump, regenerative nerve sprouts growing into all directions, as prevents or, at 
least, significantly attenuates the chain of events otherwise leading to the painful sensation referred to as denervated region ${ }^{44}$. A corresponding autotomy counteraction appears in L2-L3 spinal compression model when the stable gastric pentadecapeptide BPC 157 improves the healing course of the spinal cord injury and leads to functional recovery in rats ${ }^{45}$. As mentioned above, much like topical ophthalmic anesthetic-induced adverse effects, BPC 157 counteracts morphine-induced analgesia ${ }^{46}$ and counteracts NSAIDinduced toxicity ${ }^{7,47-55}$, also known to decrease corneal sensitivity ${ }^{56}$. Therefore, the stable gastric pentadecapeptide BPC 157 can be a quite distinctive 'healing antidote' for adverse effects of topical ophthalmic anesthetics.

Considering the combined vasoconstrictive and local anesthetic properties, BPC 157 may also have a particular effect on vasculature that may influence the duration of topical ophthalmic anesthetic effect. This may be rapid activation of the bypassing loop that occurs in the rat with infrarenal occlusion of the inferior vena cava (and thereby, resolved Virchow), much like in the rats with ischemic/reperfusion colitis, duodenal venous congestion lesions, perforated cecum, bile duct ligation induced liver cirrhosis and portal hyperten$\operatorname{sion}^{31-33,42,57}$. Accordingly, BPC 157 interacts with several molecular pathways ${ }^{1,42,58-64}$. In particular, BPC 157 increased expression and internalization of VEGFR2, activation of the VEGFR2-Akt-eNOS signaling pathway without the need of other known ligands or shear stress ${ }^{61}$.

Finally, to counteract topical ophthalmic anesthetic-induced disturbances, it may be that BPC 157 has an effect of its own on membrane potential. Inhibition of depolarization of HEK293 cells by bupivacaine in vitro fully supports that BPC 157 may, through direct action, successfully counteract the effect of topical ophthalmic anesthetics, much like the effect of bupivacaine ${ }^{14}$.

Likewise, cell depolarization due to increasing magnesium concentration was inhibited in the presence of BPC $157(1 \mu \mathrm{M})$ in vitro ${ }^{34}$. Furthermore, BPC 157 reduced depolarization caused by hyperkalemia in HEK293 cells ${ }^{15}$. Depolarization caused by BPC 157 $(1 \mu \mathrm{m})$ was inhibited by the application of the nonspecific potassium blocker $\mathrm{BaCl} 2(1 \mathrm{mM})^{15}$. In conclusion, we suggest BPC 157 as an antidote of topical ophthalmic anesthetics.

\section{Acknowledgments}

This work was supported by the Ministry of Science, Education and Sports, Republic of Croatia (grant number 108-1083570-3635) and by the Osijek Faculty of Medicine, Josip Juraj Strossmayer University of Osijek (grant code VIF2017-MEFOS-17).

\section{References}

1. Kang EA, Han YM, An JM, Park YJ, Sikiric P, Kim DH, et al. BPC157 as potential agent rescuing from cancer cachexia. Curr Pharm Des. 2018;24:1947-56. https://doi.org/10.2174/13816 12824666180614082950.

2. Seiwerth S, Brcic L, Vuletic LB, Kolenc D, Aralica G, Misic M, et al. BPC 157 and blood vessels. Curr Pharm Des. 2014; 20:1121-5.

3. Seiwerth S, Rucman R, Turkovic B, Sever M, Klicek R, Radic $\mathrm{B}$, et al. BPC 157 and standard angiogenic growth factors, gastrointestinal tract healing, lessons from tendon, ligament, muscle and bone healing. Curr Pharm Des. 2018;24:1972-89. https://doi.org/10.2174/1381612824666180712110447.

4. Sikiric P, Seiwerth S, Brcic L, Sever M, Klicek R, Radic B, et al. Revised Robert's cytoprotection and adaptive cytoprotection and stable gastric pentadecapeptide BPC 157. Possible significance and implications for novel mediator. Curr Pharm Des. 2010;16:1224-34.

5. Sikiric P, Seiwerth S, Rucman R, Turkovic B, Rokotov DS, Brcic L, et al. Stable gastric pentadecapeptide BPC 157: novel therapy in gastrointestinal tract. Curr Pharm Des. 2011;17: 1612-32.

6. Sikiric P, Seiwerth S, Rucman R, Turkovic B, Rokotov DS, Brcic L, et al. Focus on ulcerative colitis: stable gastric pentadecapeptide BPC 157. Curr Med Chem. 2010;19:126-32.

7. Sikiric P, Seiwerth S, Rucman R, Turkovic B, Rokotov DS, Brcic L, et al. Toxicity by NSAIDs. Counteraction by stable gastric pentadecapeptide BPC 157. Curr Pharm Des. 2013; 19:76-83.

8. Sikiric P, Seiwerth S, Rucman R, Turkovic B, Rokotov DS, Brcic L, et al. Stable gastric pentadecapeptide BPC 157-NOsystem relation. Curr Pharm Des. 2014;20:1126-35.

9. Sikiric P, Seiwerth S, Rucman R, Kolenc D, Vuletic LB, Drmic $\mathrm{D}$, et al. Brain-gut axis and pentadecapeptide BPC 157: theoretical and practical implications. Curr Neuropharmacol. 2016; 14:857-65.

10. Sikiric P, Seiwerth S, Rucman R, Drmic D, Stupnisek M, Kokot $\mathrm{A}$, et al. Stress in gastrointestinal tract and stable gastric pentadecapeptide BPC 157. Finally, do we have a solution? Curr Pharm Des. 2017;23:4012-28. https://doi.org/10.2174/1 381612823666170220163219.

11. Sikiric P, Rucman R, Turkovic B, Sever M, Klicek R, Radic B, et al. Novel cytoprotective mediator, stable gastric pentadecapeptide BPC 157. Vascular recruitment and gastrointestinal 
tract healing. Curr Pharm Des. 2018;24:1990-2001. https:// doi.org/10.2174/1381612824666180608101119.

12. Sikiric P, Hahm KB, Blagaic AB, Tvrdeic A, Pavlov KH, Petrovic $A$, et al. Stable gastric pentadecapeptide BPC 157, Robert's stomach cytoprotection/adaptive cytoprotection/organoprotection, Selye's stress coping response: progress, achievement, future. Gut Liver. 2019 Jun 4. https://doi.org/10.5009/gnl 18490. [Epub ahead of print]

13. Gwyer D, Wragg NM, Wilson SL. Gastric pentadecapeptide body protection compound BPC 157 and its role in accelerating musculoskeletal soft tissue healing. Cell Tissue Res. 2019 Aug; 377(2):153-9. https://doi.org/10.1007/s00441-019-03016-8.

14. Zivanovic-Posilovic G, Balenovic D, Barisic I, Strinic D, Stambolija V, Udovicic M, et al. Stable gastric pentadecapeptide BPC 157 and bupivacaine. Eur J Pharmacol. 2016;793:56-65. https://doi.org/10.1016/j.ejphar.2016.10.035.

15. Barisic I, Balenovic D, Klicek R, Radic B, Nikitovic B, Drmic $\mathrm{D}$, et al. Mortal hyperkalemia disturbances in rats are NO-system related. The life saving effect of pentadecapeptide BPC 157. Regul Pept. 2013;181:50-66. https://doi.org/10.1016/j. regpep.2012.12.007.

16. Balenovic D, Bencic ML, Udovicic M, Simonji K, Hanzevacki JS, Barisic I, et al. Inhibition of methyldigoxin-induced arrhythmias by pentadecapeptide BPC 157: a relation with NOsystem. Regul Pept. 2009;156:83-9. https://doi.org/10.1016/j. regpep.2009.05.008.

17. Bosnjak ZJ, Graf BM, Sikiric P, Stowe DF. Protective effects of newly isolated gastric peptide following hypoxic and reoxygenation injury in the isolated guinea pig heart. FASEB J. 1994; 8(4):A129.

18. Stambolija V, Stambolija TP, Holjevac JK, Murselovic T, Radonic J, Duzel V, et al. BPC 157. The counteraction of succinylcholine, hyperkalemia, and arrhythmias. Eur J Pharmacol. 2016;781:83-91. https://doi.org/10.1016/j.ejphar.2016.04.004.

19. Strinic D, Belosic Halle Z, Luetic K, Nedic A, Petrovic I, Sucic $\mathrm{M}$, et al. BPC 157 counteracts QTc prolongation induced by haloperidol, fluphenazine, clozapine, olanzapine, quetiapine, sulpiride, and metoclopramide in rats. Life Sci. 2017;186: 66-79. https://doi.org/10.1016/j.lfs.2017.08.006.

20. Masnec S, Kokot A, Zlatar M, Kalauz M, Kunjko K, Radic B, et al. Perforating corneal injury in rat and pentadecapeptide BPC 157. Exp Eye Res. 2015 Jul;136:9-15. https://doi.org/ 10.1016/j.exer.2015.04.016.

21. Lazić R, Gabrić N, Dekaris I, Bosnar D, Boban-Blagaić A, Sikirić P. Gastric pentadecapeptide BPC 157 promotes corneal epithelial defects healing in rats. Coll Antropol. 2005 Jun; 29(1):321-5.

22. Kralj T, Kokot A, Kasnik K, Drmic D, Zlatar M, Seiwerth S, Sikiric P. Effects of pentadecapeptide BPC 157 on experimental rat model of dry eye. FASEB J. 2017;31(Suppl 1):993.3.

23. Kokot A, Zlatar M, Stupnisek M, Drmic D, Radic R, Vcev A, et al. NO system dependence of atropine-induced mydriasis and L-NAME- and L-arginine-induced miosis: reversal by the pentadecapeptide BPC 157 in rats and guinea pigs. Eur J Pharmacol. 2016 Jan 15;771:211-9. https://doi.org/10.1016/j. ejphar.2015.12.016.

24. McAlvin JB, Zhan C, Dohlman JC, Kolovou PE, SalvadorCulla B, Kohane DS. Corneal anesthesia with site 1 sodium channel blockers and dexmedetomidine. Invest Ophthalmol Vis Sci. 2015 Jun;56(6):3820-6. https://doi.org/10.1167/ iovs.15-16591.

25. Brewitt H, Bonatz E, Honegger H. Morphological changes of the corneal epithelium after application of topical anaesthetic ointments. Ophthalmologica. 1980;180(4):198-206.

26. McGee HT, Fraunfelder FW. Toxicities of topical ophthalmic anesthetics. Expert Opin Drug Saf. 2007 Nov;6(6):637-40.

27. Judge AJ, Najafi K, Lee DA, Miller KM. Corneal endothelial toxicity of topical anesthesia. Ophthalmology. 1997 Sep;104 (9):1373-9.

28. Zemba M, Cilic AZ, Balenovic I, Cilic M, Radic B, Suran J, Drmic D, et al. BPC 157 antagonized the general anaesthetic potency of thiopental and reduced prolongation of anaesthesia induced by L-NAME/thiopental combination. Inflammopharmacology. 2015 Dec;23(6):329-36. https://doi.org/10.10 07/s10787-015-0249-9.

29. Sikiric P, Gyires K, Seiwerth S, Grabarevic Z, Rucman R, Petek $\mathrm{M}$, et al. The effect of pentadecapeptide BPC 157 on inflammatory non-inflammatory direct and indirect pain and capsaicin neurotoxicity. Inflammopharmacology. 1993;2:121-7.

30. Nemet A, Belkin M, Rosner M. Transplantation of newborn lacrimal gland cells in a rat model of reduced tear secretion. Isr Med Assoc J. 2007 Feb;9(2):94-8.

31. Duzel A, Vlainic J, Antunovic M, Malekinusic D, Vrdoljak B, Samara M, et al. Stable gastric pentadecapeptide BPC 157 in the treatment of colitis and ischemia and reperfusion in rats: new insights. World J Gastroenterol. 2017;23:8465-88. https:// doi.org/10.3748/wjg.v23.i48.8465

32. Drmic D, Samara M, Vidovic T, Malekinusic D, Antunovic M, Vrdoljak B, et al. Counteraction of perforated cecum lesions in rats: effects of pentadecapeptide BPC 157, L-NAME and Larginine. World J Gastroenterol. 2018;24:5462-76. https://doi. org/10.3748/wjg.v24.i48.5462.

33. Amic F, Drmic D, Bilic Z, Krezic I, Zizek H, Peklic M, et al. Bypassing major venous occlusion and duodenal lesions in rats, and therapy with the stable gastric pentadecapeptide BPC 157, L-NAME and L-arginine. World J Gastroenterol. 2018;24: 5366-78. https://doi.org/10.3748/wjg.v24.i47.5366.

34. Medvidovic-Grubisic M, Stambolija V, Kolenc D, Katancic J, Murselovic T, Plestina-Borjan I, et al. Hypermagnesemia disturbances in rats, NO-related: pentadecapeptide BPC 157 abrogates, L-NAME and L-arginine worsen. Inflammopharmacology. 2017;25:439-49. https://doi.org/10.1007/s10787-0170323-6.

35. Okamoto K, Tashiro A, Thompson R, Nishida Y, Bereiter DA. Trigeminal interpolaris/caudalis transition neurons mediate reflex lacrimation evoked by bright light in the rat. Eur J Neuro- 
sci. 2012 Dec;36(11):3492-9. https://doi.org/10.1111/j.1460 -9568.2012.08272.x.

36. Becker DE, Reed KL. Local anesthetics: review of pharmacological considerations. Anesth Prog. 2012;59:90-101. https:// doi.org/10.2344/0003-3006-59.2.90.

37. Cummins TR. Setting up for the block: the mechanism underlying lidocaine's use-dependent inhibition of sodium channels. J Physiol. 2007;582(1):11.

38. Hersh EV, Saraghi M, Moore PA. Intranasal tetracaine and oxymetazoline: a newly approved drug formulation that provides maxillary dental anesthesia without needles. Curr Med Res Opin. 2016 Nov;32(11):1919-25.

39. Erkan Turan K, Kocabeyoglu S, Bekircan-Kurt CE, Bezci F, Erdem-Ozdamar S, Irkec M. Ocular surface alterations and in vivo confocal microscopic characteristics of corneas in patients with myasthenia gravis. Eur J Ophthalmol. 2018 Sep;28(5): 541-6. https://doi.org/10.1177/1120672117753688.

40. Aykut V, Elbay A, Çigdem Uçar I, Esen F, Durmus A, Karadag $\mathrm{R}$, Oguz $\mathrm{H}$. Corneal sensitivity and subjective complaints of ocular pain in patients with fibromyalgia. Eye. 2018 Apr; 32(4):763-7. https://doi.org/10.1038/eye.2017.275.

41. Marcos-Fernández MÁ, Tabernero SS, Herreras JM, Galarreta DJ.Impact of herpetic stromal immune keratitis in corneal biomechanics and innervation. Graefes Arch Clin Exp Ophthalmol. 2018 Jan;256(1):155-61. https://doi.org/10.1007/s00417017-3826-3.

42. Vukojevic J, Siroglavic M, Kasnik K, Kralj T, Stancic D, Kokot A, et al. Rat inferior caval vein (ICV) ligature and particular new insights with the stable gastric pentadecapeptide BPC 157. Vascul Pharmacol. 2018;106:54-66. https://doi.org/ 10.1016/j.vph.2018.02.010.

43. Gjurasin M, Miklic P, Zupancic B, Perovic D, Zarkovic K, Brcic L, et al. Peptide therapy with pentadecapeptide BPC 157 in traumatic nerve injury. Regul Pept. 2010;160:33-41. https:// doi.org/10.1016/j.regpep.2009.11.005.

44. Asada H, Yamaguchi Y, Tsunoda S, Fukuda Y. The role of spinal cord activation before neurectomy in the development of autotomy. Pain. 1996;64:161-7.

45. Perovic D, Kolenc D, Bilic V, Somun N, Drmic D, Elabjer E, et al. Stable gastric pentadecapeptide BPC 157 can improve the healing course of spinal cord injury and lead to functional recovery in rats. J Orthop Surg Res. 2019;14:199. https://doi. org/10.1186/s13018-019-1242-6.

46. Boban Blagaic A, Turcic P, Blagaic V, Dubovecak M, Jelovac N, Zemba M, et al. Gastric pentadecapeptide BPC 157 counteracts morphine-induced analgesia in mice. J Physiol Pharmacol. 2009;60 Suppl 7:177-81.

47. Sikirić P, Seiwerth S, Grabarević Z, Rucman R, Petek M, Jagić $\mathrm{V}$, et al. Beneficial effect of a novel pentadecapeptide BPC 157 on gastric lesions induced by restraint stress, ethanol, indomethacin, and capsaicin neurotoxicity. Dig Dis Sci. 1996;41: 1604-14.

48. Ilic S, Drmic D, Zarkovic K, Kolenc D, Coric M, Brcic L, et al. High hepatotoxic dose of paracetamol produces generalized convulsions and brain damage in rats. A counteraction with the stable gastric pentadecapeptide BPC 157 (PL 14736). J Physiol Pharmacol. 2010;61:241-50.

49. Ilic S, Drmic D, Franjic S, Kolenc D, Coric M, Brcic L, et al. Pentadecapeptide BPC 157 and its effects on a NSAID toxicity model: diclofenac-induced gastrointestinal, liver, and encephalopathy lesions. Life Sci. 2011;88:535-42. https://doi. org/10.1016/j.lfs.2011.01.015.

50. Ilic S, Drmic D, Zarkovic K, Kolenc D, Brcic L, Radic B, et al. Ibuprofen hepatic encephalopathy, hepatomegaly, gastric lesion and gastric pentadecapeptide BPC 157 in rats. Eur J Pharmacol. 2011;667:322-9. https://doi.org/10.1016/j.ejphar.2011. 05.038

51. Stupnisek M, Franjic S, Drmic D, Hrelec M, Kolenc D, Radic $\mathrm{B}$, et al. Pentadecapeptide BPC 157 reduces bleeding time and thrombocytopenia after amputation in rats treated with heparin, warfarin or aspirin. Thromb Res. 2012;129:652-9. https:// doi.org/10.1016/j.thromres.2011.07.035.

52. Lojo N, Rasic Z, Zenko Sever A, Kolenc D, Vukusic D, Drmic $\mathrm{D}$, et al. Effects of diclofenac, L-NAME, L-arginine, and pentadecapeptide BPC 157 on gastrointestinal, liver, and brain lesions, failed anastomosis, and intestinal adaptation deterioration in 24 hour-short-bowel rats. PLoS One. 2016;11(9): e0162590. https://doi.org/10.1371/journal.pone.0162590.

53. Drmic D, Kolenc D, Ilic S, Bauk L, Sever M, Zenko Sever A, et al. Celecoxib-induced gastrointestinal, liver and brain lesions in rats, counteraction by BPC 157 or L-arginine, aggravation by L-NAME. World J Gastroenterol. 2017;23:5304-12. https: //doi.org/10.3748/wjg.v23.i29.5304.

54. Vitaic S, Stupnisek M, Drmic D, Bauk L, Kokot A, Klicek R, et al. Nonsteroidal anti-inflammatory drug-induced failure of lower esophageal and pyloric sphincter and counteraction of sphincter failure with stable gatric pentadecapeptide BPC 157 in rats. J Physiol Pharmacol. 2017;68:265-72.

55. Sikiric P, Seiwerth S, Grabarevic Z, Rucman R, Petek M, Jagic $\mathrm{V}$, et al. Pentadecapeptide BPC 157 positively affects both nonsteroidal anti-inflammatory agent-induced gastrointestinal lesions and adjuvant arthritis in rats. J Physiol Paris. 1997;91: 113-22.

56. Cantarella RA, de Oliveira JK, Dorbandt DM, Montiani-Ferreira F. Effects of topical flurbiprofen sodium, diclofenac sodium, ketorolac tromethamine and benzalkonium chloride on corneal sensitivity in normal dogs. Open Vet J. 2017;7(3):25460. https://doi.org/10.4314/ovj.v7i3.9.

57. Sever AZ, Sever M, Vidovic T, Lojo N, Kolenc D, Vuletic LB, et al. Stable gastric pentadecapeptide BPC 157 in the therapy of the rats with bile duct ligation. Eur J Pharmacol. 2019; 847:130-42. 10.1016/j.ejphar.2019.01.030.

58. Chang CH, Tsai WC, Lin MS, Hsu YH, Pang JH. The promoting effect of pentadecapeptide BPC 157 on tendon healing involves tendon outgrowth, cell survival, and cell migration. J Appl Physiol. 2011;110:774-80. https://doi.org/10.1152/japplphysiol.00945.2010. 
59. Chang CH, Tsai WC, Hsu YH, Pang JH. Pentadecapeptide BPC 157 enhances the growth hormone receptor expression in tendon fibroblasts. Molecules. 2014;19:19066-77. https://doi. org/10.3390/molecules191119066.

60. Huang T, Zhang K, Sun L, Xue X, Zhang C, Shu Z, et al. Body protective compound-157 enhances alkali-burn wound healing in vivo and promotes proliferation, migration, and angiogenesis in vitro. Drug Des Develop Ther. 2015;9:2485-99. https://doi. org/10.2147/DDDT.S82030.

61. Hsieh MJ, Liu HT, Wang CN, Huang HY, Lin Y, Ko YS, et al. Therapeutic potential of pro-angiogenic BPC157 is associated with VEGFR2 activation and up-regulation. J Mol Med. 2017;95:323-33. https://doi.org/10.1007/s00109-016-1488-y.
62. Tkalcevic VI, Cuzic S, Brajsa K, Mildner B, Bokulic A, Situm $\mathrm{K}$, et al. Enhancement by PL 14736 of granulation and collagen organization in healing wounds and the potential role of egr-1 expression. Eur J Pharmacol. 2007;570:212-21.

63. Chen Y, Wang W, Wang H, Li Y, Shi M, Li H, Yan J. Rapamycin attenuates splenomegaly in both intrahepatic and prehepatic portal hypertensive rats by blocking mTOR signaling pathway. PLoS One. 2016 Jan 6;11(1):e0141159. https://doi. org/10.1371/journal.pone.0141159.

64. Cesarec V, Becejac T, Misic M, Djakovic Z, Olujic D, Drmic D, et al. Pentadecapeptide BPC 157 and the esophagocutaneous fistula healing therapy. Eur J Pharmacol. 2013;701:203-12. https://doi.org/10.1016/j.ejphar.2012.11.055.

\title{
Sažetak \\ PENTADEKAPEPTID BPC 157 SKRAĆUJE TRAJANJE ANESTEZIJE ROŽNICE IZAZVANE TETRAKAINOM I OKSIBUPROKAINOM KOD ŠTAKORA
}

\author{
I. Mirkovic, T. Kralj, M. Lozic, V. Stambolija, J. Kovačevic, L. Vrdoljak, M. Zlatar, K. Milanovic, D. Drmic, \\ J. Predovic, S. Masnec, M. Jurjevic, M. Bušic, S. Seiwerth, A. Kokot i P. Sikiric
}

U ovom istraživanju ispitivali smo međuodnos anestezije rožnice uzrokovane $0,5 \%$ tetrakainom odnosno $0,4 \%$ oksibuprokainom i pentadekapeptida BPC 157 (0,4 $\mu \mathrm{g} / \mathrm{oko})$ u kombinaciji s inhibitorom nitrid oksida L-NAME (0,1 mg/oko) i/ili supstratom nitrid oksida L-argininom ( $2 \mathrm{mg} / \mathrm{oko})$ primijenjenim u obliku kapi za oči. Procjenjivali smo anesteziju rožnice (Cochet-Bonnetov esteziometar), nestajanje lezija rožnice (bojenje 10\% fluoresceinom) te volumen nastajanja suza (Schirmerov test). Učinak potpunog poništavanja anestezije rožnice uočen je u skupinama koje su primale BPC 157. Oporavak je također nastupio u skupinama koje su primale i supstrat i blokator nitrid oksida. L-arginin skraćuje vrijeme neosjetljivosti rožnice, a uočeno je i smanjenje lezija rožnice te poništavanje smanjenja lučenja suza, ali samo u ranijem kraćem razdoblju, dok se kasnije taj učinak gubi. L-NAME je uzrokovao produženje vremena neosjetljivosti rožnice kao i povećanje lezija rožnice te dodatno smanjenje stvaranja suza. Kada se L-arginin i L-NAME daju zajedno njihov učinak se poništava. Opažene razlike mogu ukazivati na određeni utjecaj i uključenost nitrid oksida (neosjetljivost rožnice naspram nastajanja lezija rožnice i stvaranja suza), što je pokazano primjenom supstrata/blokatora nitrid oksida. Međutim, u bilo kojoj kombinaciji prije ili kasnije, dodatak BPC 157 doveo bi do poništavanja učinka primijenjenih anestetika.

Ključne riječi: BPC 157; Tetrakain; Oksibuprokain; Anestezija rožnice; NOS; Štakori 